\title{
Molecular Characterization and Cellulolytic Capacity of Chaetomium globosum Isolates
}

\author{
Eman G. El-Dawy ${ }^{1}$, Yassmin M. Shebany ${ }^{1,2^{\star}}$ and Youssuf A. Gherbawy ${ }^{1}$ \\ ${ }^{1}$ Botany and Microbiology Department, Faculty of Science, South Valley University, Qena, Egypt. \\ ${ }^{2}$ Biology Department, Faculty of Science, Taif University, Taif, Saudi Arabia.
}

\begin{abstract}
Authors' contributions
This work was carried out in collaboration among all authors. Author EGED designed the study, carried out practical experiments, wrote the protocol and wrote the first and final draft of the manuscript. Author YMS performed the statistical analysis and some practical experiments and managed the literature searches. Author YAG wrote the first and final draft of the manuscript. All authors read and approved the final manuscript.

Article Information

DOI: 10.9734/ARRB/2020/v35i930267

Editor(s):

(1) Dr. Viduranga Y. Waisundara, Australian College of Business and Technology, Sri Lanka.

(2) Dr. Bechan Sharma, University of Allahabad, India.

(3) Dr. Paola Angelini, University of Perugia, Italy.

Reviewers:

(1) Akhilesh Bind, Sam Higginbottom University of Agriculture, Technology and Sciences, India.

(2) Mona Saud Al. Ahmadi, Imam Abdulrahman Bin Faisal University (IAU), Saudi Arabia.

(3) Olaolu Oyedeji, Obafemi Awolowo University (OAU), Nigeria.

Complete Peer review History: http://www.sdiarticle4.com/review-history/60067
\end{abstract}

Original Research Article

Received 12 June 2020

Accepted 18 August 2020

Published 27 August 2020

\begin{abstract}
Chaetomium species are saprophytic fungi, have the ability to degrade cellulose with hydrolytic enzymes. Hydrolytic enzymes are a cluster of enzymes, which have the flexibility of breaking down complicated molecules into smaller molecules. The objective of this study was to clarify the genetic diversity among the isolated Chaetomium population by using PCR-based methods, along with the study of their cellulolytic activities. Chaetomium spp. were isolated from twenty-eight samples of Cuminum cyminum and Pimpinella anisum, and identified morphologically and molecularly by ITS1 and ITS4 primers. The sequencing indicated that all the isolates of Chaetomium had a $99 \%$ sequence identity with Chaetomium globosum sequences from GenBank. Molecular techniques with Internal Transcribed Spacer (ITS) region sequencing and specific genes random primers polymerase chain reaction (SGRP-PCR) showed the existence of high DNA polymorphism of Chaetomium globosum. All isolates were tested for their ability of cellulases production. Nine of the
\end{abstract}


thirteen isolates of Chaetomium globosum could produce cellulases. There are variations between C. globosum isolates and the source of the isolates and their habitat do not correlate to their ability to secrete cellulases.

Keywords: Saprophyticfungi; Chaetomium globosum; cellulases; ITS region; SGRP-PCR.

\section{INTRODUCTION}

Chaetomium is a genus of filamentous and dematiaceous fungus. It is found in air, soil and debris of plants [1]. Furthermore, researchers have indicated that these are cosmopolitan and prevalent components of various ecosystems in a wide range of environmental and climatic zones [1]. Chaetomium species exhibited significant infections to human, and the number of infections in increasing [1]. The infections include onychomycosis [2], keratitis [3] and subcutaneous [4]. Some of these species are neurotropic and thermophilic [5]. The genus contains various species with the most common ones being Chaetomium strumarium, Chaetomium funicola, Chaetomium atrobrunneum and Chaetomium globosum [6].

Chaetomium species belong to the ascomycetes (Sordariales). Chaetomium species are characterized by their superficial ascomata (mostly ostiolate perithecia) surrounded by hairs of various types [6]. Chaetomium is distributed worldwide and exist on various substrates as saprotrophs. Several types of Chaetomium species are coprophilous, cellulolytic, toxigenic and even pathogenic for humans [6].

Deoxyribonucleic acid (DNA) barcoding of Chaetomium could be a fast and precise strategy for recognition utilizing short DNA groupings [7]. The Internal Transcribed Spacer (ITS) of nuclear "Ribosomal Deoxyribonucleic Acid (rDNA)" is one of the most thoroughly sequenced molecular markers [8]. The sequence comparison of the ITS region is used for scientific categorization and molecular phylogeny since its simple structure make it amplifiable even from very little amounts of DNA, due to the high copy number of "Ribosomal ribonucleic acid (rRNA)" genes. The ITS region encompasses a high level of variation even between closely related species [9].

Hydrolytic enzymes are a group of enzymes, with the flexibility of breaking down complicated molecules into smaller molecules, such as cellulases that are capable of breaking down cellulose into aldohexoses. Cellulase is a family of enzymes hyrolysing $\beta$-1,4- glycosidic bonds of intact cellulose and other related cellooligosaccharide derivatives. Cooperation action of three principal types of the enzymes, viz., endoglucanase, exoglucanase, and $\beta$ glucosidase. Endoglucanases responsible for hydrolyzing the amorphous (internal) regions of the fibrils randomly by degrading $\beta$-glucosidic bonds; cellobiohydrolases are exoglucanases releasing cellobiose, from the ending of the chains, while $\beta$-glucosidases complete the hydrolyzing cellobiose and other cellodextrins with a low degree of polymerization to glucose units [10]. Fungi and several species of bacteria have the capability to secrete cellulases, and it has been indicated that the ability of fungi is significantly higher to secrete cellulases[10] as compared to various species of microorganisms. The most well known cellulolytic fungal species are Trichoderma sp., Humicola sp., Penicillium sp., Chaetomium sp. and Aspergillus sp. [11].

The aim of this work was to identify Chaetomium species, which were isolated from contaminated two types of spices. The genetic diversity of the isolated Chaetomium species was compared using PCR-based methods, and matched with their cellulolytic activities.

\section{MATERIALS AND METHODS}

\subsection{Study Area}

The study was carried out at Botany \& Microbiology Department, Mycology lab, Egypt, from January, 2017 to April, 2018.

\subsection{Isolation of Chaetomium Strains}

Thirteen different isolates of Chaetomium globosum were recovered from twenty-eight seed samples of two spices (14 samples were isolated from Cuminum cyminum and the other 14 samples from Pimpinella anisum). The spice seed samples were gathered from different markets in Qena city of Egypt, by using dilutionplate method on modified Czapek's Dox agar medium (by adding $20 \mathrm{~g} / \mathrm{L}$ of cellulose instead of glucose). Rose Bengal $(0.1 \mathrm{mg} / \mathrm{ml})$ and chloramphenicol $(0.5 \mathrm{mg} / \mathrm{L})$ were used as bacteriostatic agents [12] (Table 1). 


\subsection{Morphological Identification Chaetomium Strains}

The Chaetomium isolates were purified by culturing single spores on modified Czapek's Dox agar medium. A preliminary characterization was conducted using macro- and microscopic observations and measurements, including colony colour, the diameter of asci, ascospores, perithecium, perithecial hairs and their morphology. In this respect, the Chaetomium isolates were identified according to [13].

\subsection{DNA Extraction}

Chaetomium isolates were cultured in $250 \mathrm{ml}$ flasks containing $50 \mathrm{ml}$ Potato -Dextrose Broth (PDB) for 2 days by using a rotary shaker for $25^{\circ} \mathrm{C}$ at a speed of $120-150 \mathrm{rpm}$. The mycelium was separated by filtration and grounded to a fine powder in liquid nitrogen. Fifty $\mathrm{mg}$ of the powder was transferred to a $1.5 \mathrm{ml}$ Eppendorf tube and mixed with $0.7 \mathrm{ml} 2 x$ CTAB buffer (cetyltrimethyl ammonium bromide) and vortexed for 2 minutes. Eppendorf tubes were incubated at $65^{\circ} \mathrm{C}$ for 60 to 80 minutes, and $0.7 \mathrm{ml}$ of chloroform was added and mixed briefly. The samples were centrifuged at $15.000 \mathrm{rpm}$ for 10 minutes, and the supernatant was transferred into a new tube and mixed with $0.6 \mathrm{ml}$ isopropanol, chilled to $20^{\circ} \mathrm{C}$ and centrifuged at $15.000 \mathrm{rpm}$ for 5 minutes. The pellet was washed twice by $1 \mathrm{ml}$ of $70 \%$ ethanol, followed by centrifugation steps for 3 minutes at maximum speed. After drying under vacuum the sample was dissolved in $0.1 \mathrm{ml}$ TE $(10 \mathrm{mMTris}, 1 \mathrm{mM}$ EDTA, and $\mathrm{pH}$ 7.5) buffer [14]. The DNA quantity and quality were assayed by electrophoresis on a $1.4 \%$ agarose gel stained with ethidium bromide and visualized by UV trans-illumination.

\subsection{Polymerase Chain Reaction Amplification for ITS Region and Sequencing}

Polymerase chain reaction (PCR) amplification was done on a thermal cycler (Molecular Mycology, Laboratory, South Valley University, Egypt), with a reaction volume of $25 \mu \mathrm{L}$. The reaction mix included the DNA sample (about $100 \mathrm{ng})$, dNTPs Mix (200 $\mu \mathrm{mol} / \mathrm{L})$, ITS1(CTTGGTCATTTAGAGGAAGTAA) and ITS4(TCCTCCGCTTATTGATATGC) primers $(0.1 \mu \mathrm{mol} / \mathrm{L}$ each) [15]. Taq DNA polymerase (2.5 $\mathrm{U})$, and $1 \mathrm{X}$ buffer. The amplification reaction was: two minutes pre-denaturation at $94^{\circ} \mathrm{C}$, one minute denaturation under the same condition, one minute annealing at $55^{\circ} \mathrm{C}$, and two minutes extension at $72^{\circ} \mathrm{C}$. The process was recycled for 30 times, and a final extension of 10 minutes at $72^{\circ} \mathrm{C}$. The amplified products of full length ITS regions were separated by electrophoresis in $1.2 \%$ agarose gel in Tris EDTA-acetate (TAE) buffer (1X), stained with ethidium bromide at 0.5 $\mu \mathrm{g} / \mathrm{ml}$, run at $80 \mathrm{~V}$ for 3 hours. The DNA was visualized under UV light and photographed with gel documentation unit (Syngene Inc., Cambridge, UK). The sequencing was performed by the Macrogen Company (South Korea).

\subsection{Sequence Analysis}

Maximum parsimony phylogenetic analyses were conducted by using PAUP*4.0b10 (Swofford, 2000) on the ITS data set. Bayesian analyses [16] were performed by MrBayes 3.1 [17]. The best fit models were determined by using the AIC criterion as implemented in Mr Model test version 2.3 [18].

\subsection{Genetic Diversity of C. globosum Isolates}

A single pair of specific primers (SGRP-PCR), identified as good random primers [19] were used in this study. SGRP-PCR was used to study genetic diversity among collected isolates of C. globosum. Primers Opa1 (CGG TGC TTC ATC ACC TTA G), Bt2a (GGTAACCAAATCGGTGCTGCTTTC) and Tef1 (GCY CCY GGH CAY CGT GAY TTY AT). Bt2a, Opa1 and Tef1 were used as arbitrary primers. Amplifications were carried out as described by [20], PCR reactions were done in $25 \mu \mathrm{L}$ reaction mixture by the following: $12.5 \mu \mathrm{L}$ PCR Master Mix (Jena Bioscience), $0.5 \mu \mathrm{L} \mathrm{MgCl2,} 0.04 \mu \mathrm{L}$ Taq polymerase, $3 \mu \mathrm{L}$ of each primer, $1 \mu \mathrm{L}$ template DNA, and $8 \mu \mathrm{L}$ PCR water. PCR conditions were: 1 step for denaturation at $94{ }^{\circ} \mathrm{C}$ for $2.30 \mathrm{~min}$ followed by 40 cycles of : $94{ }^{\circ} \mathrm{C}$ for $45 \mathrm{~s} ; 36^{\circ} \mathrm{C}$ for $40 \mathrm{~s} ; 72^{\circ} \mathrm{C}$ for $2 \mathrm{~min}$; and an additional cycle at $72^{\circ} \mathrm{C}$ for $10 \mathrm{~min}$. The PCR products were resolved by electrophoresis on $1.4 \%$ agarose gel in $0.5 \times$ Tris-borate-EDTA buffer, at $125 \mathrm{~V}$ for $2 \mathrm{~h}$. Gels were stained by ethidium bromide and photographed under UV light using UVP Biolmaging CDS 8000 System (UVP). Dendrograms based on the banding profiles were obtained by the unweighted-pair group method with arithmetic average based on CAP software. 
Table 1. The list of Chaetomium globosum isolates and their CMase activity studied in this investigation

\begin{tabular}{lllll}
\hline $\begin{array}{l}\text { isolates } \\
\text { numbers }\end{array}$ & $\begin{array}{l}\text { Code in South } \\
\text { Valley University } \\
\text { Culturecollection }\end{array}$ & Source isolates & $\begin{array}{l}\text { CMase activity } \\
\text { [cm] }\end{array}$ & $\begin{array}{l}\text { Gen Bank } \\
\text { accession } \\
\text { numbers }\end{array}$ \\
\hline 1 & CgSVU1 & Cuminum cyminum & 9 & MG885806 \\
2 & GgSVU2 & Cuminum cyminum & - ve & MG885807 \\
3 & GgSVU3 & Pimpinella anisum & 4.5 & MG885808 \\
4 & GgSVU4 & Pimpinella anisum & 4.45 & MG885809 \\
5 & GgSVU5 & Pimpinella anisum & 1.9 & MG885811 \\
6 & GgSVU6 & Pimpinella anisum & - ve & MG885812 \\
7 & GgSVU7 & Cuminum cyminum & 7.25 & MG885813 \\
8 & GgSVU8 & Cuminum cyminum & 9 & MG885814 \\
9 & GgSVU9 & Pimpinella anisum & 1.75 & MG885816 \\
10 & CgSVU10 & Cuminum cyminum & - ve & MG885817 \\
11 & GgSVU11 & Cuminum cyminum & 7 & MG885818 \\
12 & CgSVU12 & Cuminum cyminum & 1.6 & MG885820 \\
13 & CgSVU13 & Cuminum cyminum & - ve &
\end{tabular}

\subsection{Screening of Chaetomium globosum Isolates for Cellulolytic Activity}

Liquid fermentations were carried out in $250 \mathrm{ml}$ Erlenmeyer flasks containing a modified CzapekDox broth medium $(50 \mathrm{ml})$. Each flask was autoclaved at $121^{\circ} \mathrm{C}$ for 20 minutes. After cooling, each flask was inoculated by $0.5 \mathrm{ml}$ of the spore suspension (prepared in Tween-80 $(0.2 \%, v / v)$, from 4 days and nights). Then the inoculated flasks were incubated at periods in an incubator (5 days). The content of the flasks were filtered through a muslin cloth. The filtrate was centrifuged at $10,000 \mathrm{rpm}$ for 10 minutes and the supernatant was used for the determination of cellulase enzyme activity [21]. Cellulase production was assayed by using a minimal agar medium containing $(\mathrm{g} / \mathrm{L})$ : yeast extract, $1 ; \mathrm{K}_{2} \mathrm{HPO}_{4}, 4 ; \mathrm{NaCl}, 2 ; \mathrm{MgSO}_{4} .7 \mathrm{H}_{2} \mathrm{O}, 1$; $\mathrm{MnSO}_{4}, 0.05 ; \mathrm{FeSO}_{4} .7 \mathrm{H}_{2} \mathrm{O}, 0.05 ; \mathrm{CaCl}_{2} .2 \mathrm{H}_{2} \mathrm{O}$, 2; $\mathrm{NH}_{4} \mathrm{Cl}$, 2; agar, 20 and distilled water at $\mathrm{pH}$ 6.0. The medium was supplemented by $1 \%(\mathrm{w} / \mathrm{v})$ carboxymethyl cellulose (CMC) and point inoculated by $1 \mathrm{ml}$ of the Chaetomium filtrate. After incubation, $3 \mathrm{ml}$ aqueous solution of congo red $(0.1 \% \mathrm{w} / \mathrm{v})$ was added to the plates for 30 minutes. The plates were washed by $1 \mathrm{ml}$ of $\mathrm{NaCl}$ solution $(1 \mathrm{M})$ and left to dry for 15 minutes [22]. The formation of clear zones around the colonies indicated cellulolytic activity by the isolates.

\section{RESULTS}

\subsection{Sequence Characteristics}

The ITS sequences compared with accessible sequences from the GenBank nucleotide database, indicated that the DNA sequences from all C. globosum isolates studied had $99 \%$ similar sequence identity with $C$. globosum sequences from GenBank (Table, 1). A neighbour-Joining tree was employed to study genetic diversity among thirteen strains from $C$. globosum, branches corresponding to partitions reproduced in less than $50 \%$ bootstrap replicates are collapsed; tree length= 599; consistency index $(\mathrm{Cl})=0.0 .8848$; homoplasy index $(\mathrm{HI})=$ 0.0 .1152 ; retention index $(\mathrm{RI})=0.6550$; rescaled consistency index $(R C)=0.5795$, as it is shown in Fig. 1. Comparison of ITS sequences with sequences accessible within the GenBank nucleotide database indicated that the deoxyribonucleic acid sequences from all thirteen isolates of $C$. globosum collected during this study had $99 \%$ sequence identity with $C$. globosum sequences from GenBank. The phylogenic tree revealed that the strains could be divided into 6 different clades and one strain (root) was achieved from the Genbank. The phylogenetic tree was rooted by FJ878052, which was obtained from Genebank. No correlation was found between the habitat and isolates' source. For example, strains MG885815 and MG885816 were grouped together with $99 \%$ bootstrap value, although they were isolated from anise andcumin seeds, respectively.

\subsection{SGRP-PCR Characterization of C. globosum Isolates}

Thirteen isolates of C. globosum were used to study the genetic diversity of $C$. globosum population isolated from the spices samples. In this respect, specific genes random primers polymerase chain reaction (SGRP-PCR) 
technique was employed using three different primers (Fig. 2).

The three primers produced 37 SGRP/ PCR loci (183 fragments). Across strains percentage of polymorphism were 100\% (no missing bands were observed). Phylogenetic analysis was carried out to detect the evolutionary relationship across species using the Cap method. The phylogenetic tree was presented in (Fig. 3). The phylogenetic tree consists of two large clades, the first clade comprised of MG885817 and MG885820. The second clade was divided into two lineages, MG885818 occupied a single lineage on its own, and the rest of the strains were assembled in another lineage. These results confirmed that $C$. globosum is a complex group with different subspecies.

\subsection{Cellulase Screening}

The thirteen isolates of $C$. globosum were tested for their ability to produce cellulase enzymes. The cellulase production varied among the C. globosum isolates. Nine of the 13 isolates of $C$. globosum showed capability to produce cellulase as shown with the congo red dye. The halos ranged from $1.6 \mathrm{~cm}$ to $9 \mathrm{~cm}$ in diameter. Four of the isolates of $C$. globosum did not show any reaction with congo red dye as was shown in Table (1) and Fig. (4).

\section{DISCUSSION}

The ITS region sequencing helpful in the identification at the species level or close to species level, alignment of the ITS region between major groups of fungi and even at intervals order and families was found to be useful sometimes [23]. These results are in agreement with [19] who collected ten isolates from various substrates that constituted one clade in the phylogenetic tree, including $C$. globosum with $98 \%$ bootstrap value. The results presented here confirmed the variations between species level of C.globosum. Chandra, et al. [24] studied forty four isolates of Chaetomium (fifteen isolates C. globosum) and subjected them to PCR amplification of the genes; $\beta$-tubulin, actin, calmodulin, tef-1 and rpb2. The sequences were subjectedto maximum parsimony phylogenetic analysis. The clustering obtained was compared bythe ITS based clustering. It was found that ITS region indicated the best grouping of the Chaetomium species through phylogeny although the cluster of $C$. globosum had several sub clades. Aggarwal, et al. [25] showed that ITS sequence data could differentiate 18 different isolates of the Chaetomium spp. were collected from different climates. Aggarwal, et al. [26] designed specific marker for identification of $C$. globosum to distinguish it from other different species of Chaetomium by forming a unique region of genomic DNA.

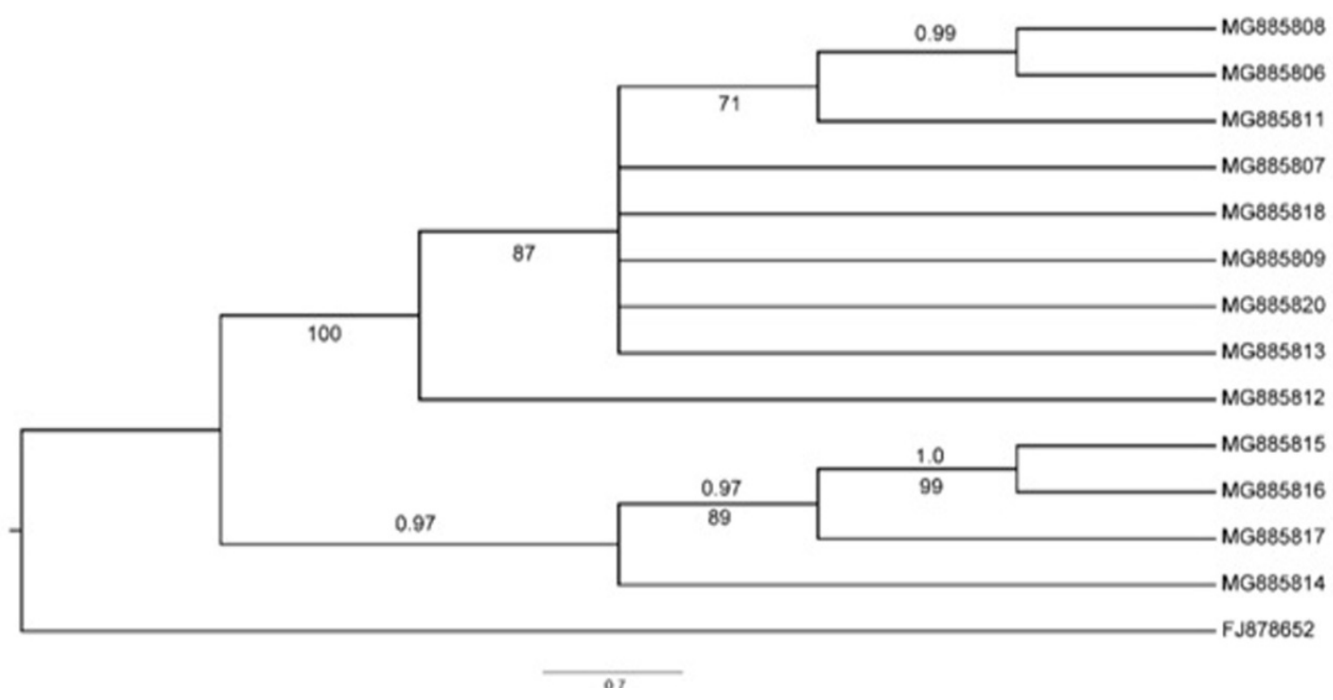

Fig. 1. Strict consensus cladogram of 9 Most Parsimonious (MP) trees found using the ITS sequence data showing the phylogenetic relationships among Chaetomium globosum

isolates. Values above the branches indicate Bayesian posterior probabilities $(\geq 0.95)$, and the maximum parsimony bootstrap support values $(\geq 70 \%)$ are given below the branches. The GenBank accession numbers of $C$. globosum were appeared besides the branches 


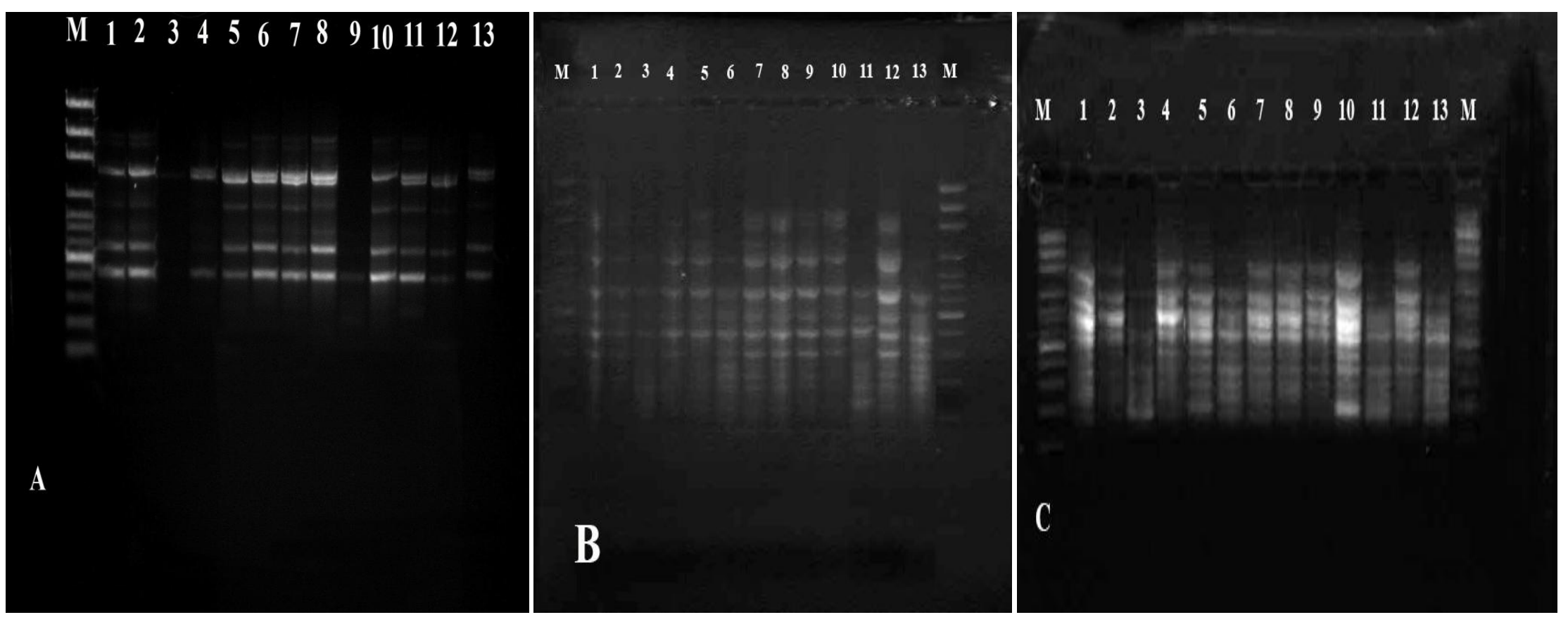

Fig. 2. DNA banding patterns from specific genes random primers polymerase chain reaction analysis of Chaetomium globosum isolates primed by Opa1 (A), Bt2a (B) and Tef1(C) primers. Lane Mis a 1-kb DNA ladder and lane 1-13 no. of isolates 


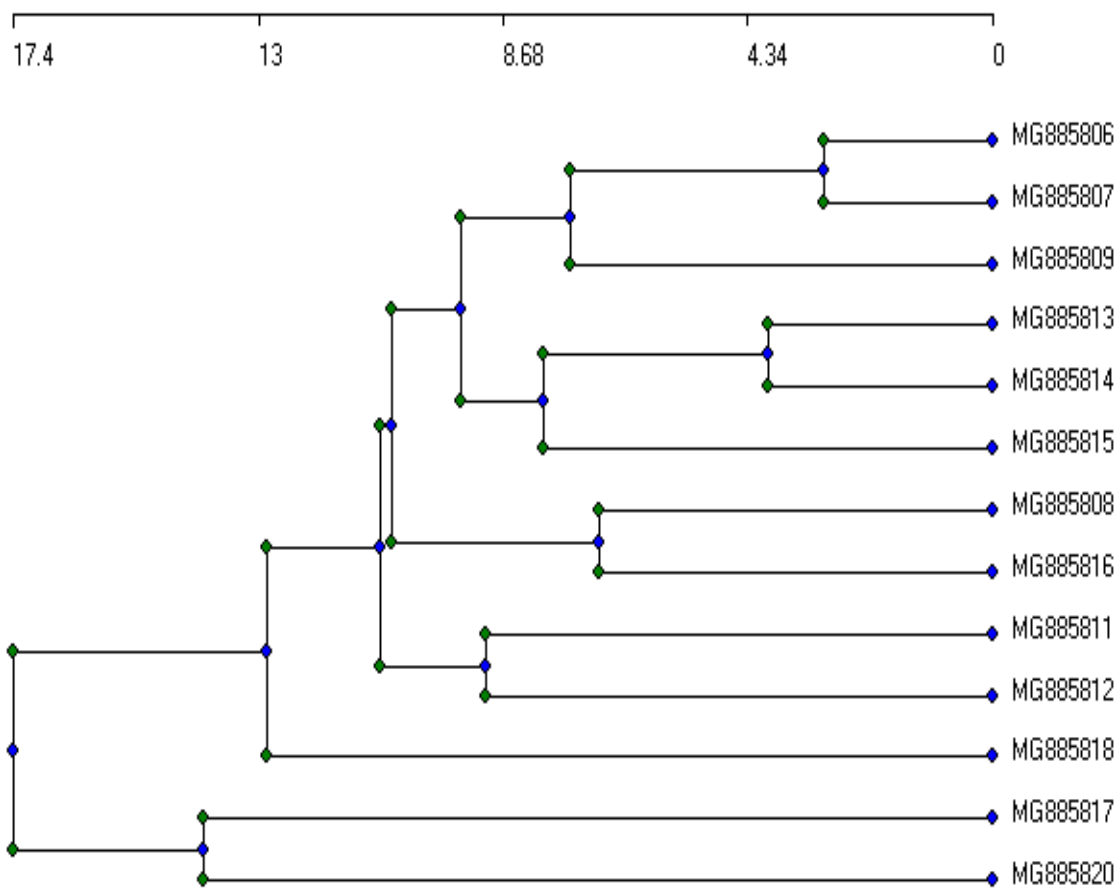

Fig. 3. Average linkage tree illustrating the relationship among the different isolates of $C$. globosum on the analysis of specific genes random primers polymerase chain reaction by using CAP software

A

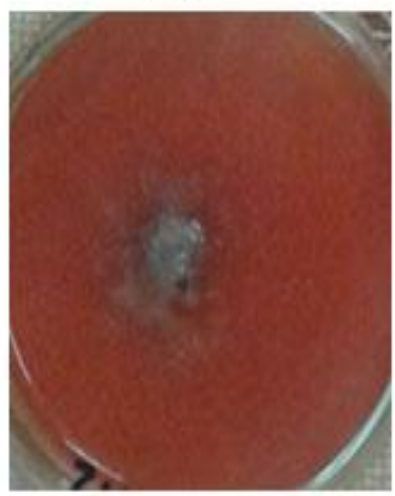

B

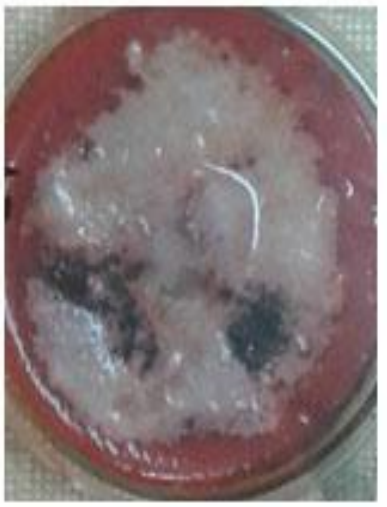

$\mathrm{C}$

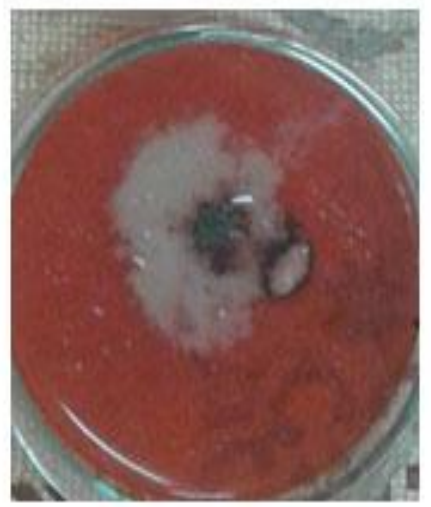

Fig. 4. Chaetomium globosum showed reaction with Congo red dyein $B$ and $C$ (= Positive isolates producing cellulase) and $A=$ Negative isolate producing cellulase

The polymorphic fragmented patterns were found to occur by slight varieties in intensity. With the used primers, each isolate yielded up to 1 to 7 bands. Faint bands were only considered when consistently found in different experiments. It could be depicted that bands of higher intensities might be due to the amplification of repetitive sequences or the influence of neighbouring sequences on annealing to the target sequence or might have been generated because of a lower degree of mismatch between primer and the target sequence [27].

The SGRPI PCR findings confirmed the molecular identification by the ITS region. It is clear that there are significant differences under the species level of $C$. globosum. The results of the present phylogenetic analysis are similar to 
the results of [19] on C. globosum isolates from various substrates.

Nine isolates of $C$. globosum produced cellulase with halo diameters ranging from $1.6 \mathrm{~cm}$ to $9 \mathrm{~cm}$. Gupta, et al. [28] showed that CMC acts as an authentic indicator of cellulolytic ability. Isolated Chaetomium strains were primarily screened by employing an activity zone technique with acidbase indicator dye (congo red dye). Also, it was recognized that acid-base indicator dye could be a metachromatic dye, which is capable of reacting with the polysaccharide. The CMC is stained red to deep pink. Once the treatment of CMC with cellulase protein, the excess dye was washed gently by $\mathrm{NaCl}$. Subsequently, the observation was created to notice the substrate utilization zone around the colony. On the other hand, unstained areas indicated the regions where the $C M C$ have broken down to $\beta$ 1. Suryadi, et al. [29] found that Chaetomium globosum has a high ability of cellulase production (by forming clear zone around the filtrate, $45 \mathrm{~mm}$ ). Longoni, et al. [30] reported the functional role of two cellulases of $C$. globosum involved in preliminary degradation of plant cell wall polymers and also pointed to the functional role of other enzymes involved in cellulose degradation.

\section{CONCLUSION}

Identification of C. globosum with ITS1 and ITS4 primers is suggested to be used as a primary tool and need confirmation with more specific primers because there are several subspecies of $C$. globosum with the same morphological characters and similar to C. globosum species and these differences were confirmed by using SGRP/ PCR technique. Strains of C. globosum may be more helpful in the industrial production of cellulases.

\section{DISCLAIMER}

The products used for this research are commonly and predominantly use products in our area of research and country. There is absolutely no conflict of interest between the authors and producers of the products because we do not intend to use these products as an avenue for any litigation but for the advancement of knowledge. Also, the research was not funded by the producing company rather it was funded by personal efforts of the authors.

\section{COMPETING INTERESTS}

Authors have declared that no competing interests exist.

\section{REFERENCES}

1. Abdel-Azeem AM. Recent developments on genusChaetomium, Springer Nature Switzerland AG, Fungal Biol; 2020. Available:https://doi.org/10.1007/978-3030-31612-9_1

2. Kim DM, Lee MH, Suh MK, Ha GY, Kim H, Choi JS. Onychomycosis caused by Chaetomium globosum. Ann. Dermat. 2013;24(2):232-236.

3. Kaliamurthy J, Kalavathy CM, Jesudasan C, Thomas PA. Case report. Keratitis due to Chaetomium sp. Ophthalmol. Med. Art. 2011;ID 696145:3 pages.

4. Yu J, Yang S, Zhao Y, Li R. A case of subcutaneous phaeohyphomycosis caused by Chaetomium globosum and the sequences analysis of $C$. globosum. Med. Myco. 2006;44:541-5.

5. Attia E, Abdel-Azeem AM. Chaetomium in indoor environment and medically important species of Chaetomium. Recent Developments on Genus Chaetomium, Publisher: Springer Nature Switzerland AG 2020; 2019.

6. Kubatova A. Chaetomium in the Czech Republic and notes to three new records. Czech Myco. 2006;58:155-171.

7. Siddall ME, Fontanella FM, Watson SC, Kvist S, Erseus C. Barcoding bamboozled by bacteria: convergence to metazoan mitochondrial primer targets by marine microbes. Syst. Biol. 2009;58(4):445-451.

8. Bulat SA, Lübeck M, Mironenko N, Jensen DF, Lübeck PS. UP-PCR analysis and ITS1 ribotyping of strains of Trichoderma and Gliocladium. Mycol. Res. 1998;102(8):933-943.

9. Álvarez I, Wendel JF. Ribosomal ITS sequences and plant phylogenetic inference. Mol. Phyl. Evol. 2003;29:417434.

10. Sajith S, Priji P, Sreedevi S, Benjamin S. An overview on fungal cellulases with an industrial perspective. J. Nut. Food Sci. 2016;60(10):1-13.

11. Gupta P, Samant K, Sahu A. Isolation of cellulose-degrading bacteria and determination of their cellulolytic potential. Inter. J. Microb. 2012;578925:1-5.

12. Al-Doory Y. Laboratory medical mycology. P. 410 Lea \& Febiger Philadelphia Kimpton Publishers, London; 1980.

13. Arx JAV, Guarro J, Figueras MJ. The ascomycete genus Chaetomium. Beihefte Nova Hedwigia. 1986;84:1-162. 
14. Moeller M, Maurer H, Rosler M. MDMA in blood, urine and hair: $A$ forensic case, in Nagata T (Ed.), Proceeding 30th TIAAFT Meeting, Yoyod Printing Kaisha Ltd., Foukouka Jaban. 1992;56-61.

15. White TJ, Bruns TD, Lee SB, Taylor JW. Amplification and direct sequencing of fungal ribosomal RNA genes for phylogenetics. In: Innis, M.A., Gelfand, D.H., Sninsky JJ, White TJ, Eds. PCR Protocols: A Guide to Methods and Applications, Academic Press, New York. 1990;315-322.

16. Huelsenbeck JP, Ronquist F, Nielsen R, Bollback JP. Bayesian inference of phylogeny and its impact on evolutionary biology. Sci. 2001;294:2310-2314.

17. Ronquist F, Huelsenbeck JP. MrBayes 3: Bayesian phylogenetic inference under mixed models. Bioinform. 2003;19:15721574.

18. Nylander JA. Mr Model test. Program distributed by the author. Evolutionary Biology Centre, Uppsala University; 2004.

19. Abdel-azeem AM, Gherbawy YA, Sabry AM. Enzyme profiles and genotyping of Chaetomium globosum isolates from various substrates. Plant Biosyst. 2016;150:420-428.

20. Fungaro MHP, Vieira MLC, PizziraniKleiner AA, de Azevedo JL. Diversity among soil and insect isolates Metarhizium anisopliae var. anisopliae detected by RAPD. Lett. Appl. Microb. 1996;22:389392.

21. Deswal D, Khasa YP, Kuhad RC. Optimization of cellulase production by a brown rot fungus Fomitopsis sp. RCK2010 under solid state fermentation. Biores. Techn. 2011;102:6065-6072.

22. Das A, Bhattacharya S, Roopa KS, Yashoda SS. Microbial utilization of agronomic waste for cellulase production by Aspergillus niger and Trichoderma viride using solid-state fermentation.
Dynamic Biochemistry, Pro. Biotechn. Mole.Biol. 2011;5:18-22.

23. Seifert KA. Barcoding fungi, Progress towards DNA barcoding of fungi. Mol. Ecol. Res. 2009;9(1):83-89.

24. Chandra Sekhar V, Prameeladevi T, Kamil D, Ram D. Studies on Phylogeny of Chaetomium Species of India. Inter. J. Curr. Microb. App. Sci. 2018;7(8):31543166.

25. Aggarwal R, Kharbikar LL, Sharma S, Gupta S, Yadav A. Phylogenetic relationships of Chaetomium isolates based on the internal transcribed spacer region of the rRNA gene cluster. Afri. J. Biotech. 2013;12(9):914-920.

26. Aggarwal R, Sharma S, Gupta S, Shuka R. Development of conventional and real time PCR assay for the rapid detection and quantification of a biocontrol agent, Chaetomium globosum. J. Plant Pathol. 2014;96(3):477-485.

27. Welsh J, Peters NC, Mcclelland M. Polymorphisms generated by arbitrarily primed PCR in the mouse: Application to strain identification and genetics. Nucl. Acids Res. 1991;19:303-306.

28. Gupta C, Jain P, Kumar D, Dixit AK, Jain RK. Production of cellulase enzyme from isolated fungus and its application as efficient refining aid for production of security paper. Inter. J. App. Microb. Biotech. Res. 2015;3:11-19.

29. Suryadi H, Lestari YPI, Yanuar MA. Potential of cellulose of Chaetomium globosum for preparation and characterization of microcrystalline cellulose from water hyacinth (Eichhornia crassipes) Inter. J. App. Pharm. 2019;11(4):140-146.

30. Longoni P, Rodolfi M, Pantaleoni L, Doria E, Concia L, Picco AM, Cella R. Functional analysis of the degradation of cellulosic substrates by a Chaetomium globosum endophytic isolate. App. Envir. Microb. 2012;78(10):3693-3705.

(c) 2020 El-Dawy et al.; This is an Open Access article distributed under the terms of the Creative Commons Attribution License (http://creativecommons.org/licenses/by/4.0), which permits unrestricted use, distribution, and reproduction in any medium, provided the original work is properly cited.

Peer-review history:

The peer review history for this paper can be accessed here: http://www.sdiarticle4.com/review-history/60067 